\title{
Efficacy and safety of mycophenolate mofetil for IgA nephropathy: An updated meta-analysis of randomized controlled trials
}

\author{
JIAN-NAN ZHENG, TONG-DAN BI, LIN-BO ZHU and LIN-LIN LIU
}

Department of Nephrology, The First Affiliated Hospital of China Medical University, Shenyang, Liaoning 110001, P.R. China

Received November 25, 2017; Accepted May 11, 2018

DOI: $10.3892 /$ etm.2018.6418

\begin{abstract}
The efficacy and safety of mycophenolate mofetil (MMF) for immunoglobulin A nephropathy ( $\operatorname{IgAN}$ ) remains debatable. Therefore, the present meta-analysis was conducted with randomized controlled trials (RCTs). PubMed/MEDLINE, EMBASE and the Cochrane Central Register of Controlled Trials were analyzed to identify eligible trials. The pooled risk ratio (RR) with $95 \%$ confidence interval (CI) was estimated for all the dichotomous outcome measures. A total of eight RCTs with nine publications ( $\mathrm{n}=510$ patients) were included. No significant difference was noted between therapeutic regimens with and without MMF for renal remission and end stage renal disease (ESRD) of patients with IgAN (seven trials; RR, 1.250; 95\% CI, 0.993-1.574; $\mathrm{P}=0.057$; and four trials; RR, 0.728; 95\% CI, 0.164-3.236; $\mathrm{P}=0.676$ ). To further define the effects of MMF for renal remission, subgroup analysis was performed, demonstrating that MMF was significantly more effective compared with the placebo (three trials; RR, 2.152; 95\% CI, 1.198-3.867; P=0.010), although the immunosuppressive regimens with MMF had no significantly different effects compared with those without MMF (four trials; RR, 1.140; 95\% CI, 0.955-1.361; $\mathrm{P}=0.146$ ), indicating that MMF was superior to placebo and had a similar efficacy to other immunosuppressants for renal remission. In addition, subgroup analysis for ESRD revealed no significant differences between MMF and placebo and between the immunosuppressive regimens with and without MMF (three trials; RR, 0.957; 95\% CI, 0.160-5.726; $\mathrm{P}=0.962$; and one trial; RR, 0.205; 95\% CI, 0.010-4.200; $\mathrm{P}=0.303$ ). Furthermore, there were no significant differences between the therapeutic regimens with and without $\mathrm{MMF}$ in terms of the risk of adverse events. The present meta-analysis demonstrated that
\end{abstract}

Correspondence to: Professor Lin-Lin Liu, Department of Nephrology, The First Affiliated Hospital of China Medical University, 155 Nan Jing North Street, He Ping, Shenyang, Liaoning 110001, P.R. China

E-mail: catherine-11@126.com

Key words: mycophenolate mofetil, immunoglobulin A nephropathy, renal remission, end-stage renal disease, randomized controlled trial, meta-analysis
MMF was more effective compared with the placebo, may have similar efficacy to other immunosuppressants in terms of inducing renal remission of IgAN and may not increase the risk of adverse events. The long-term effects of MMF on the prognosis of patients with $\mathrm{IgAN}$ require verification in further studies.

\section{Introduction}

Immunoglobulin A nephropathy (IgAN) is the most common form of primary glomerulonephritis globally (1). According to the International Kidney Biopsy Survey, IgAN was diagnosed in $22 \%$ of all glomerular diseases in Europe and in up to $39 \%$ in Asia (2). The clinical manifestations of $\operatorname{IgAN}$ are variable, ranging from isolated hematuria to rapidly progressive renal dysfunction. Correspondingly, the histological lesions are diverse, ranging from mild mesangial proliferative glomerulonephritis to crescentic glomerulonephritis. Approximately $50 \%$ of patients with IgAN develop end-stage renal disease (ESRD) within 30 years, which indicates that $\operatorname{Ig} A N$ is an important cause of ESRD (3).

The pathological lesions of $\operatorname{Ig} \mathrm{AN}$ are characterized by mesangial IgA (primarily IgA1) deposits, viewed by immunofluorescence, frequently concomitant with the deposition of IgG and complement factor 3 (1). Therefore, IgAN is considered to be an immune-mediated kidney disease and is treated through administration of immunosuppressive treatments, including mycophenolate mofetil (MMF) (4). Mycophenolic acid (MPA) is an active compound derived from MMF, which inhibits inosine 5'-monophosphate dehydrogenase reversibly and non-competitively and is essential for de novo biosynthesis of guanine nucleotides and lymphocyte proliferation $(5,6)$. MMF has been commonly used in patients undergoing solid organ transplantation $(7,8)$ and in recent years it has been applied in IgAN. However, the efficacy and safety of MMF in IgAN remains controversial. Randomized controlled trials (RCTs) and previous meta-analyses led to inconsistent conclusions (9-21). Various studies have determined that there were no differences between therapeutic regimens that did and did not utilize MMF in patients with $\operatorname{IgAN}(10,12,15,16)$. However, other studies have demonstrated that the therapeutic regimens with MMF were superior to those without $(11,13,14,17)$. The previously published meta-analyses also demonstrated different results; some demonstrated the superiority of MMF for $\operatorname{IgAN}(19,21)$, but others failed to exhibit any 
difference $(18,20)$. Therefore, the efficacy and safety of MMF for IgAN is yet to be fully elucidated. To examine the efficacy and safety of MMF for IgAN, a meta-analysis of RCTs was performed in the present study on the basis of the most complete evidence.

\section{Materials and methods}

Data sources and searches. Two independent assessments of the literature were performed using three computerized databases, PubMed/MEDLINE (https://www.ncbi.nlm.nih. gov/pubmed/), EMBASE (https://www.embase.com/login) and the Cochrane Central Register of Controlled Trials (CCRCT; http://www.cochranelibrary.com), prior to October 2017. The following medical subject heading terms and text words were used: Mycophenolate mofetil, mycophenolic acid and $\operatorname{Ig} \mathrm{A}$ nephropathy. The searches were restricted to clinical trials in the three databases. No language restriction was applied.

Study selection and outcome measures. Two independent assessments evaluated all retrieved titles and abstracts for eligibility and a detailed evaluation by full-text review of the publications that were likely to meet the inclusion criteria was performed. The present meta-analysis included RCTs, which investigated efficacy and/or safety of MMF for patients with IgAN and reported at least one outcome measure, including primary endpoint of renal remission (i.e., complete and partial remission) and secondary endpoints of ESRD and adverse events. The original definitions of complete and partial remission were very similar among the included trials and were therefore applied in the present meta-analysis. Any disagreement or uncertainty was discussed for consensus.

Study quality assessment. The methodological quality of the included RCTs was assessed twice, according to Cochrane recommendations and the Preferred Reporting Items for Systematic Reviews and Meta-Analyses guidelines $(22,23)$. The following six items were considered for the assessment of methodological quality: Adequate generation of randomization, blinding, allocation concealment, incomplete outcome data, selective outcome reporting and possible sources of other bias. The procedure of assessment was performed according to the following criteria: 'Yes' (low risk) or adequate, if the item was described clearly and adequately; 'no' (high risk) or inadequate, if the item was not described adequately; or 'unclear' if the information was insufficient to judge the risk of bias as 'low' or 'high.' The quality of assessment was evaluated using the $\kappa$ statistic. $\kappa$ statistic was calculated with the following formula: $\kappa=\left(p_{0}-p_{e}\right) /\left(1-p_{e}\right), p_{0}=(a+d) /(a+b+c+d), p_{e}=p_{y e s}+p_{n o}, p_{y e s}=$ $(a+b) /(a+b+c+d) \cdot(a+c) /(a+b+c+d), p_{n o}=(c+d) /(a+b+c+d) \cdot(b+d) /$ $(a+b+c+d)$. Where a, b, c, and d represent the data in the 4-fold table.

Data extraction and synthesis. Two independent data extractions of the characteristics of the included RCTs (country, sample size, study period, regimens of the treatment and control groups, definitions of complete and partial remission and duration of follow-up), study population (age, sex, population setting, clinical and laboratory parameters) and outcome measures (renal remission, ESRD and adverse events) were performed.

The pooled risk ratio (RR) with $95 \%$ confidence interval (CI) was estimated for all dichotomous outcome measures. Heterogeneity was assessed with Cochran's Q test (heterogeneity $\chi^{2}$ ) and $\mathrm{I}^{2}$ and $\mathrm{H}$ statistics. Since the estimated intervention effects in the included trials were not consistent, data synthesis was performed using the random effects model (Knapp-Hartung method). Random effects meta-regression was performed to examine the sources of heterogeneity by evaluating the correlations between $\log R$ Rs of the primary endpoint and co-variables [characteristics of the population and the included trials that may be associated with outcomes (sex, age, population settings, country, laboratory parameters at baseline and the periods of follow-up)]. Subgroup analysis was applied when the source of heterogeneity was identified. Publication bias was investigated using Egger's regression analysis and visual examination of funnel plots.

Stata 11.0 (StataCorp LLC, College Station, TX, USA) was used for all analytical procedures. Two-sided P-values $<0.05$ were considered to indicate a statistically significant difference and $\mathrm{P}<0.10$ was applied for heterogeneity tests.

\section{Results}

Description of included trials. A total of 42 publications were identified in the trial selection process following exclusion of duplications from the three electronic databases (PubMed/MEDLINE, EMBASE and CCRCT). The screening process is summarized in Fig. 1. A total of 20 articles were excluded in the first round, including 16 irrelevant articles and four reviews, and 22 full-text articles were further evaluated for eligibility. A further 13 publications were excluded for the following reasons: One as non-RCT, six as study protocols of clinical trials and six as multiple publications. Consequently, eight RCTs with nine publications (9-17) (510 participants) were included in the present meta-analysis to evaluate the efficacy and safety of MMF for patients with IgAN. Tang et al $(13,14)$ reported short-term and long-term outcomes of the same trial in two publications.

The baseline characteristics of trials and study populations are listed in Table I. The population refers to patients with overt proteinuria; patients with severe renal dysfunction were excluded. Renal pathological lesions were considered as inclusion criteria in six of the included trials. Four of the eight included trials compared MMF with a placebo and the other four trials compared immunosuppressive regimens with and without MMF. Mean ages and percentage of male patients ranged from 28.5 to 42.7 years and from 35.0 to $84.4 \%$, respectively. The periods of follow-up ranged between 6 and 72 months. Furthermore, the definitions of renal remission (i.e., complete remission and partial remission) in the included trials are described in Table II, illustrating similarities.

Methodological quality assessment was accomplished with a high estimated level of consistence ( $\kappa$ statistic $=1.0$ ), which is described in detail in Table III. The sequence generation was adequate in three trials and unclear in five trials due to insufficient information. Allocation concealment was adequate in two trials and unclear in the other six. Blinding was performed adequately in two trials, inadequately in two and was unclear 

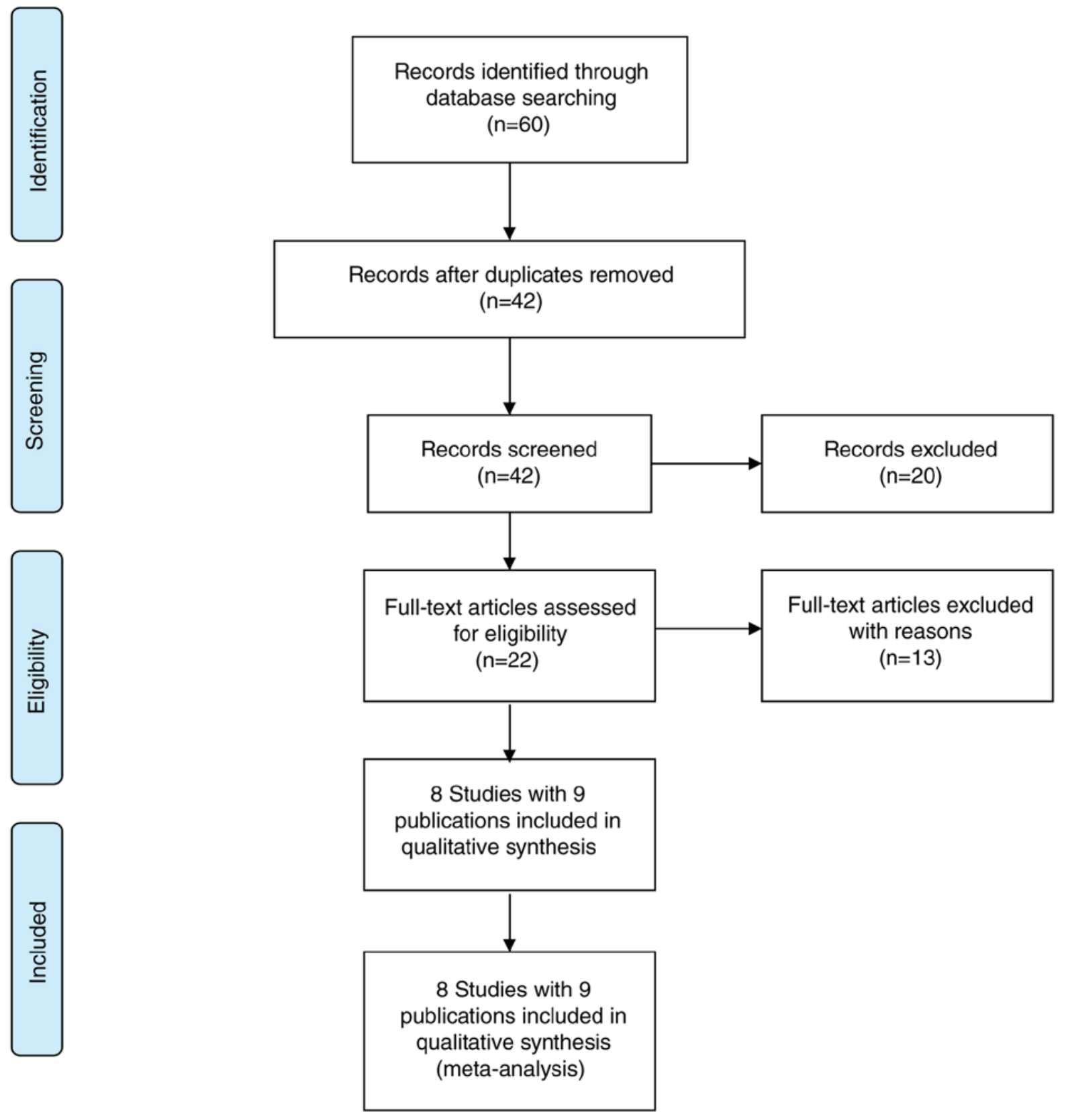

Figure 1. Flow chart of study selection process.

in four. Incomplete outcome data were addressed adequately in six trials and inadequately in two. Selective reporting was adequate in six trials and inadequate in two. A total of six trials were free of other bias, one trial was unclear and one trial had a high risk of bias due to early termination.

Effect of MMF on renal remission. A total of seven trials with 478 participants reported data on renal remission. The funnel plots exhibited asymmetry (Fig. 2A). Egger's regression analysis demonstrated no significant publication bias $(\mathrm{P}=0.297$; Fig. 2B). The pooled effects (RRs) were homogeneous $\left(I^{2}=36.0 \% ; \mathrm{Q}=9.38\right.$, degrees of freedom, $\mathrm{df}=6 ; \mathrm{P}=0.153 ; \mathrm{H}=1.3$; 95\% CI, 1.0-1.9) according to the random effects model and there was no significant difference between therapeutic regimens with and without MMF for renal remission in patients with IgAN (Fig. 3A; RR, 1.250; 95\% CI, 0.993-1.574; P=0.057).
Random effects meta-regression was performed, which indicated no significant interactions between treatment effect, trial and population characteristics. Further subgroup analysis was performed according to the therapeutic regimens in the control groups of a placebo or other immunosuppressants, which demonstrated that MMF was significantly superior compared with a placebo (Fig. 3B; three trials; RR, 2.152; 95\% CI, 1.198-3.867; $\mathrm{P}=0.010)$. The immunosuppressive regimens with MMF had no significantly different effects compared with immunosuppressive regimens without MMF (Fig. 3B; four trials; RR, 1.140; 95\% CI, 0.955-1.361; P=0.146).

Effect of MMF on ESRD. A total of four trials with 282 participants reported data on ESRD. The included effects (RRs) were heterogeneous $\left(\mathrm{I}^{2}=54.0 \% ; \mathrm{Q}=6.53, \mathrm{df}=3\right.$; $\mathrm{P}=0.089 ; \mathrm{H}=1.35 ; 95 \% \mathrm{CI}, 1.0-2.6)$ according to the 


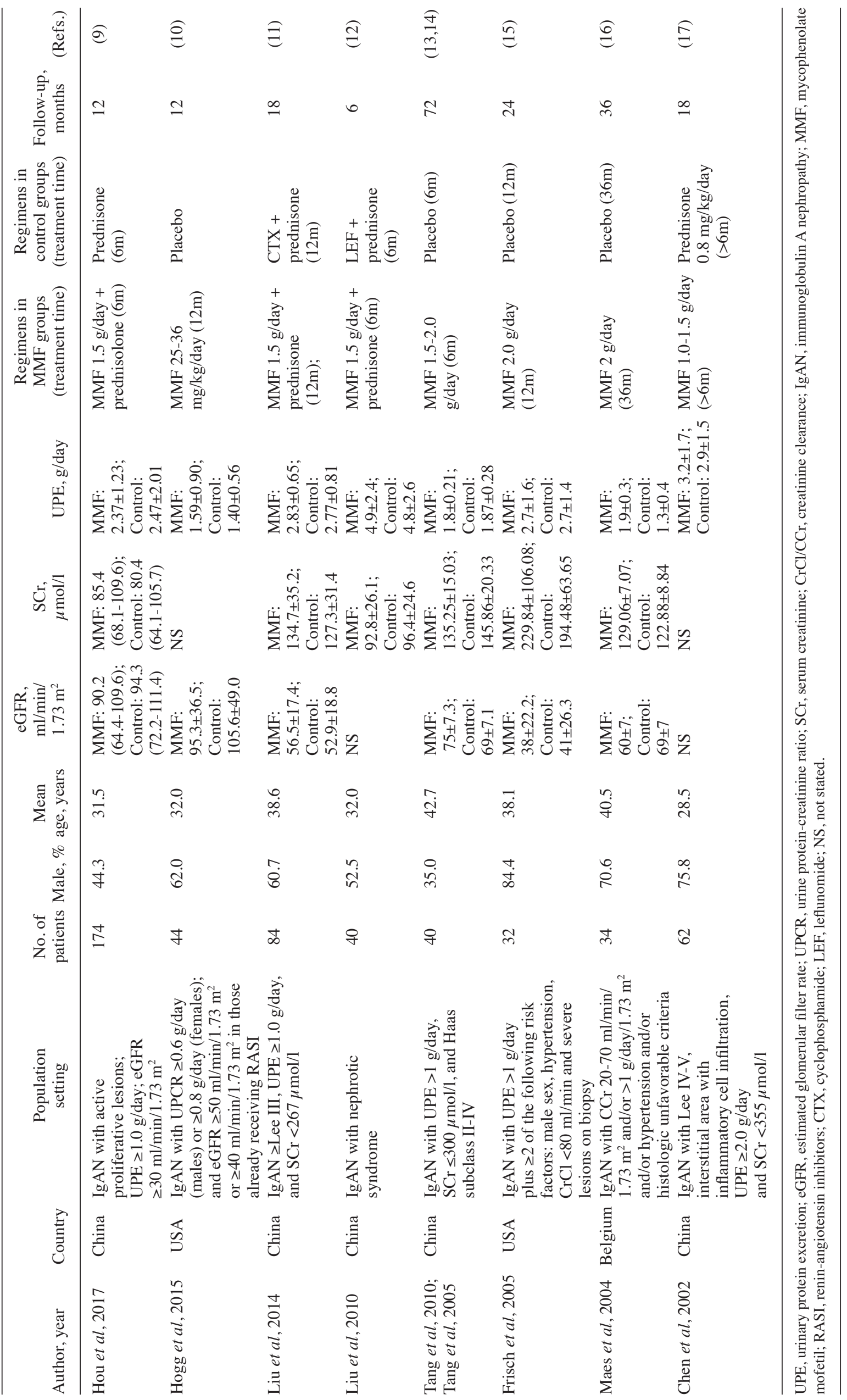


Table II. Definitions of renal remission in the included trials.

\begin{tabular}{|c|c|c|c|}
\hline Author, year & Complete remission & Partial remission & (Refs \\
\hline Hou et al, 2017 & $\begin{array}{l}\text { Undetectable proteinuria and a stable } \\
\text { SCr level ( } \leq 25 \% \text { above the baseline) }\end{array}$ & $\begin{array}{l}0.4<\mathrm{UPE}<1.0 \mathrm{~g} / \text { day, serum albumin level } \geq 35 \mathrm{~g} / \mathrm{l} \text {, } \\
\text { and stable } \mathrm{SCr}(\leq 25 \% \text { above the baseline })\end{array}$ & $(9)$ \\
\hline Hogg et al, 2015 & $\mathrm{UPCR}<0.2 \mathrm{~g} / \mathrm{g}$ & UPCR $<50 \%$ of level at time of randomization & $(10)$ \\
\hline Liu et al, 2014 & $\begin{array}{l}\mathrm{UPE}<0.4 \mathrm{~g} / \mathrm{day} \text {, serum albumin } \\
>35 \mathrm{~g} / \mathrm{l} \text { and stable renal function }\end{array}$ & $\begin{array}{l}\text { UPE declined from } \geq 50 \% \text { of the basal value, with } \\
\text { stable renal function }\end{array}$ & $(11)$ \\
\hline Liu et al, 2010 & $\begin{array}{l}\text { UPE }<0.3 \mathrm{~g} / \text { day, normal levels of } \\
\text { serum albumin and } \mathrm{SCr} \text { and } \\
<5 / \mathrm{HP} \text { RBCs in urinary sediment }\end{array}$ & $\begin{array}{l}\text { UPE } 0.3-3.0 \mathrm{~g} / \text { day or reduced to } \geq 50 \% \text { of that before } \\
\text { therapy, serum albumin level } \geq 30 \mathrm{~g} / 1 \text {, stable or } \\
\text { improved renal function and the decreased RBC } \\
\text { count in the urinary sediment }\end{array}$ & $(12)$ \\
\hline Tang et al, 2005 & $\mathrm{UPE}<0.3 \mathrm{~g} /$ day & $\begin{array}{l}\text { Decline of UPE } \geq 50 \% \text { over baseline value, but } \\
\text { UPE }>0.3 \mathrm{~g} / \text { day }\end{array}$ & (14) \\
\hline Frisch et al, 2005 & NS & $\geq 50 \%$ decrease in proteinuria & $(15)$ \\
\hline Chen et al, 2002 & $\begin{array}{l}\mathrm{UPE}<0.2 \mathrm{~g} / \text { day and normal renal } \\
\text { function }\end{array}$ & $\begin{array}{l}\geq 50 \% \text { decrease in proteinuria and } \mathrm{SCr} \text { decreased to } \\
\text { normal level or declined } \geq 50 \% \text { of basal level }\end{array}$ & $(17)$ \\
\hline
\end{tabular}

$\mathrm{SCr}$, serum creatinine; UPCR, urine protein-creatinine ratio; UPE, urinary protein excretion; HP, high power field; NS, not stated; RBC, red blood cell.

Table III. Risk analysis of potential bias.

\begin{tabular}{|c|c|c|c|c|c|c|c|}
\hline Author, year & $\begin{array}{l}\text { Adequate } \\
\text { sequence } \\
\text { generation }\end{array}$ & $\begin{array}{c}\text { Adequate } \\
\text { allocation } \\
\text { concealment }\end{array}$ & Blinding & $\begin{array}{c}\text { Address } \\
\text { incomplete } \\
\text { outcome data }\end{array}$ & $\begin{array}{c}\text { Selective } \\
\text { outcome } \\
\text { report }\end{array}$ & $\begin{array}{c}\text { Free of } \\
\text { other bias }\end{array}$ & (Refs.) \\
\hline Hou et al, 2017 & Yes & Yes & Yes & Yes & Yes & Yes & $(9)$ \\
\hline Hogg et al, 2015 & Yes & Unclear & Unclear & No & No & Yes & (10) \\
\hline Liu et al, 2014 & Unclear & Unclear & Unclear & Yes & Yes & Yes & (11) \\
\hline Liu et al, 2010 & Unclear & Unclear & Unclear & Yes & Yes & Yes & (12) \\
\hline Tang et al, 2005 & Unclear & Unclear & No & Yes & Yes & Yes & (14) \\
\hline Frisch et al, 2005 & Yes & Yes & Yes & Yes & Yes & $\mathrm{No}^{\mathrm{a}}$ & $(15)$ \\
\hline Maes et al, 2004 & Unclear & Unclear & Unclear & No & No & Unclear & (16) \\
\hline Chen et al, 2002 & Unclear & Unclear & No & Yes & Yes & Yes & (17) \\
\hline
\end{tabular}

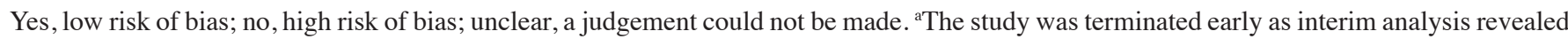
no MMF benefit.
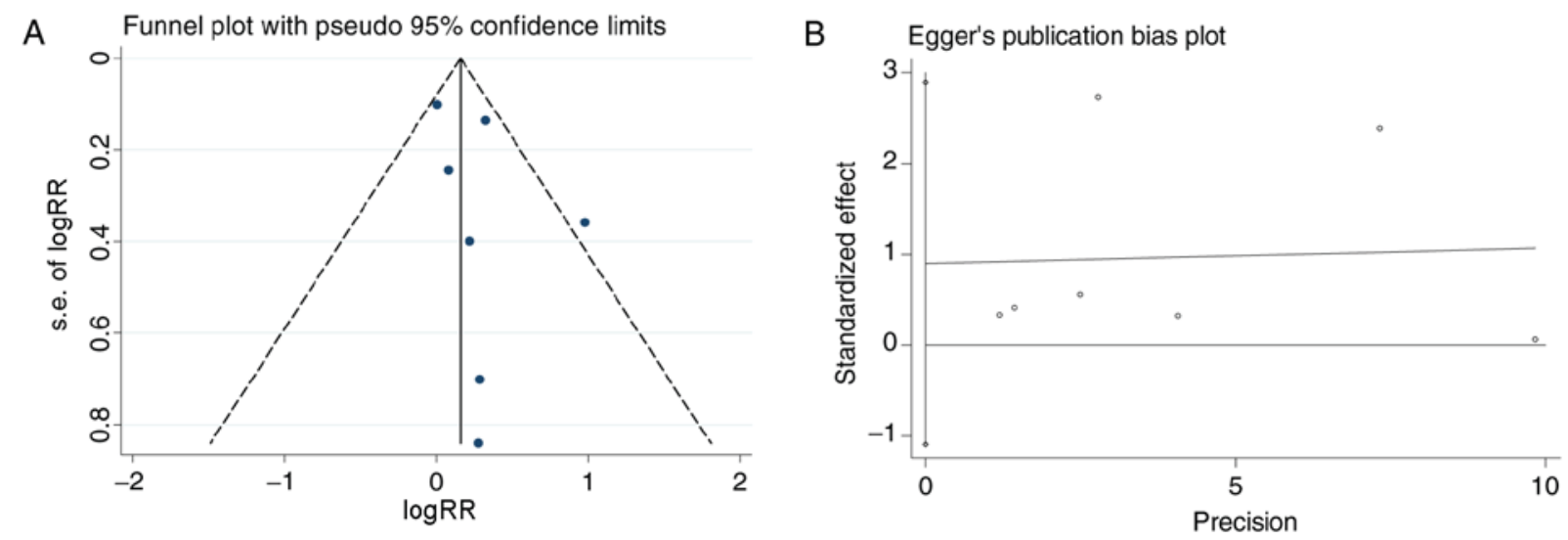

Figure 2. Publication bias. (A) Funnel plots and (B) Egger's regression analysis. RR, risk ratio; s.e., standardized effect. 

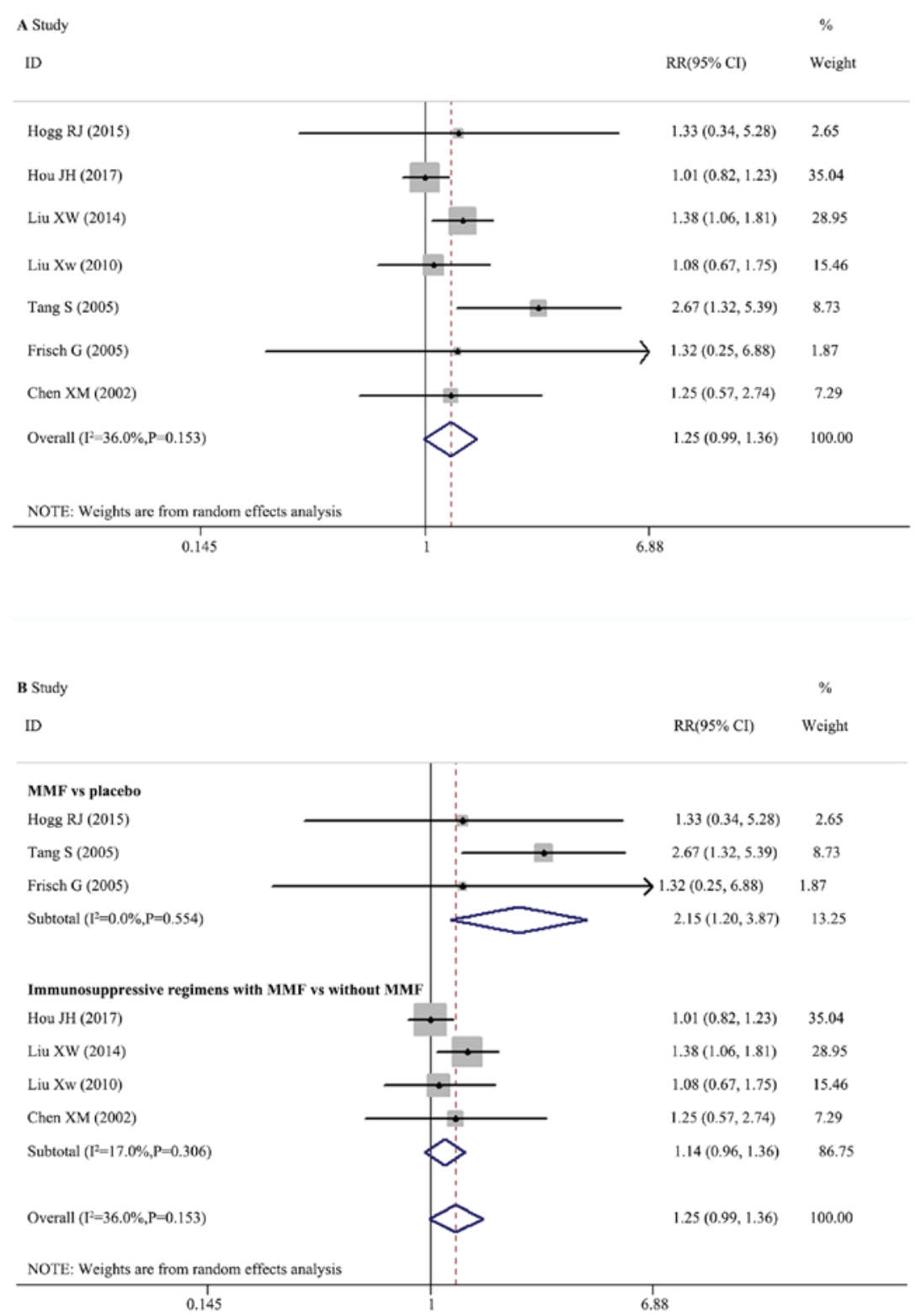

Figure 3. (A) Meta-analysis of the effect of MMF on renal remission in patients with IgAN; (B) subgroup analysis of renal remission rates according to different therapeutic regimens. MMF, mycophenolate mofetil; IgAN, immunoglobulin A nephropathy; RR, risk ratio; CI, confidence interval.

random effects model. The pooled RR was 0.728 (95\% CI, 0.164-3.236), which demonstrated that the therapeutic regimens with MMF had no significantly different effects on the ESRD of patients with IgAN compared with regimens without MMF (Fig. 4A; P=0.676). Subgroup analysis based on therapeutic regimens illustrated that there were no significantly different effects on the risk of ESRD between MMF and a placebo (three trials; RR, 0.957; 95\% CI, 0.160-5.726; $\mathrm{P}=0.962$ ) and between the immunosuppressive regimens with MMF and without MMF (Fig. 4B; one trial; RR, 0.205; 95\% CI, 0.010-4.200; $\mathrm{P}=0.303$ ).

Adverse events. Data on adverse events were analyzed (Fig. 5), indicating no significant difference between the therapeutic regimens with and without MMF in terms of the risk of gastrointestinal symptoms (seven trials; $n=471$; RR, 0.913; 95\% CI, 0.458-1.821; $\mathrm{P}=0.796$ ), diarrhea (three trials; $\mathrm{n}=142 ; \mathrm{RR}, 4.092$; 95\% CI, 0.698-24.000; $\mathrm{P}=0.118$ ), infections (seven trials; $\mathrm{n}=654 ; \mathrm{RR}, 1.350 ; 95 \%$ CI, 0.963-1.892; $\mathrm{P}=0.081)$, leukopenia (one trial; $\mathrm{n}=84$; RR, 0.333; 95\% CI, 0.014-7.956; $\mathrm{P}=0.497$ ), hepatic dysfunction (three trials; $\mathrm{n}=299 ; \mathrm{RR}, 0.797 ; 95 \% \mathrm{CI}$, 0.369-1.719; $\mathrm{P}=0.562$ ), alopecia (two trials; $\mathrm{n}=259$; $\mathrm{RR}, 0.446$; 95\% CI, 0.170-1.173; $\mathrm{P}=0.102$ ) and menstrual disorders (one trial; $\mathrm{n}=84$; RR, 0.143; 95\% CI, 0.008-2.683; $\mathrm{P}=0.193$ ).

\section{Discussion}

The present meta-analysis of RCTs demonstrated that therapeutic regimens with or without MMF did not have significantly different effects on the rates of renal remission, ESRD or adverse events for patients with IgAN. Subgroup analyses indicated that MMF was superior to the placebo for renal remission, although not different for ESRD. In addition, immunosuppressive regimens with MMF had no significantly different effects for renal remission or ESRD compared with immunosuppressive regimens without MMF. 

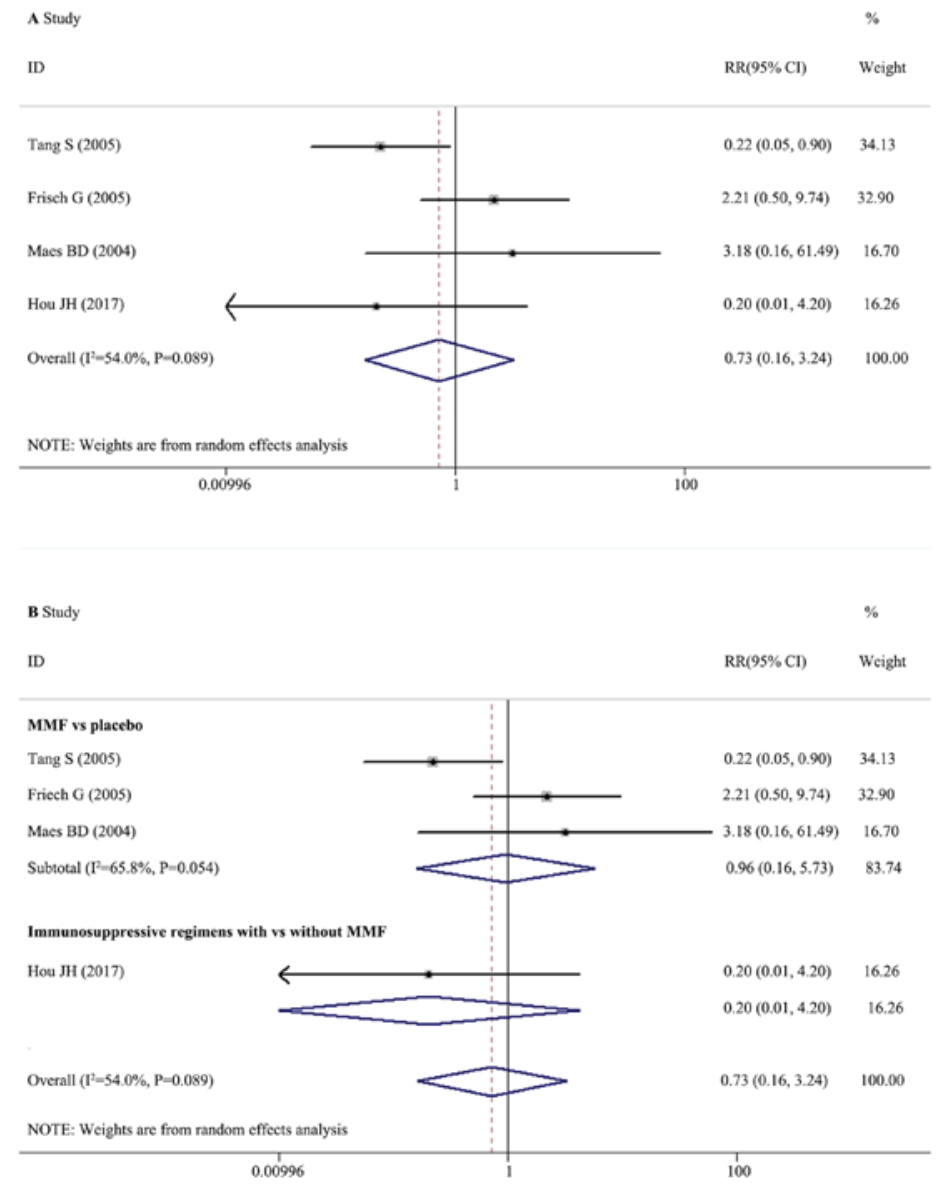

Figure 4. (A) Meta-analysis of the effect of MMF on ESRD in patients with IgAN; (B) subgroup analysis of ESRD rates according to different therapeutic regimens. MMF, mycophenolate mofetil; ESRD, end-stage renal disease; IgAN, immunoglobulin A nephropathy; RR, risk ratio; CI, confidence interval.

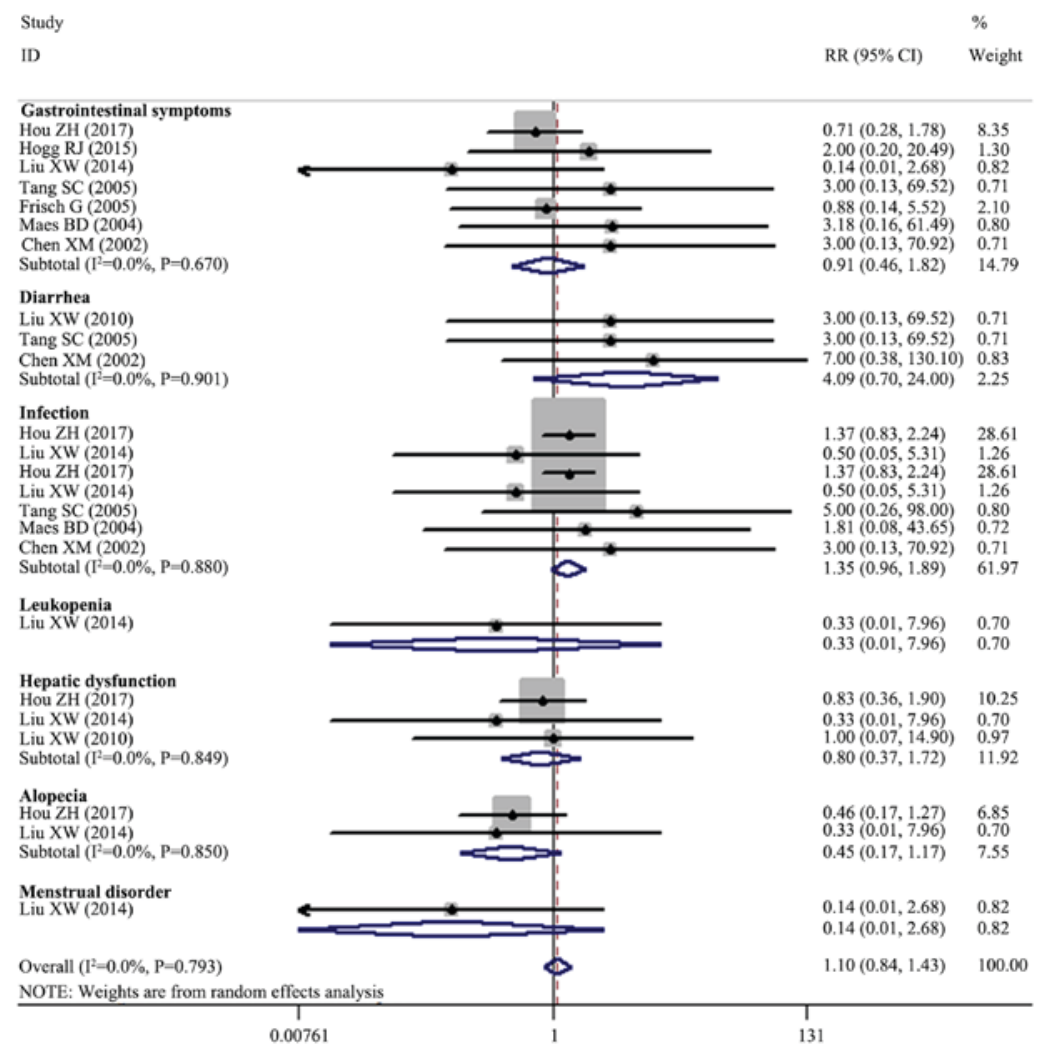

Figure 5. Meta-analysis of the adverse events of therapeutic regimens with and without MMF. MMF, mycophenolate mofetil; RR, risk ratio; CI, confidence interval. 
MMF is an immunosuppressive agent, which was first introduced into clinical practice to prevent allograft rejection (24). Subsequently, the clinical application of MMF broadened substantially and it has become part of the first line of treatment in certain types of glomerulonephritis, including lupus nephritis $(25,26)$. MMF is hydrolyzed by esterases in the intestine and blood to release MPA. MPA is able to deplete the pool of deoxyguanosine triphosphate and decrease $\mathrm{T}$ and $\mathrm{B}$ lymphocyte proliferation by inhibiting inosine 5'-monophosphate dehydrogenase, the rate-limiting enzyme of de novo purine synthesis $(27,28)$. It is additionally able to induce apoptosis in immune cells and inhibit the synthesis of fucose- and mannose-containing membrane glycoproteins, altering the surface expression and binding ability of adhesion molecules (6). MPA additionally exerts a direct effect on nonimmune cells, including inhibiting the activation of mesangial cells (28-30). IgAN is an immune-mediated kidney disease and the activation of mesangial cells is a vital part of the pathogenesis of $\operatorname{Ig} \mathrm{AN}(31,32)$. A recent study reported that MMF was able to improve endocapillary hypercellularity and cellular/fibrocellular crescents (33). However, RCTs and previous meta-analyses failed to reach consistent results on the efficacy and safety of MMF in IgAN. At present, this question remains a hot topic in clinical research.

The present meta-analysis of all RCTs, which analyzed the efficacy and safety of MMF in IgAN, including recently published trials (9-11), may supply comprehensive evidence on the use of MMF in IgAN. MMF was superior to placebo for renal remission, but not for ESRD. The majority of included RCTs in the present meta-analysis had short periods of follow-up (6-72 months), which may influence the evaluation of the effects on ESRD. Furthermore, immunosuppressive regimens with MMF exhibited no significant difference on renal remission or ESRD compared with the immunosuppressive regimens without MMF, suggesting that MMF may have a similar therapeutic effect to other immunosuppressants. Additionally, therapeutic regimens with MMF exhibited no significantly different risk of adverse events compared with those without MMF, indicating that MMF did not add to the risk of adverse events.

There are limitations to the present meta-analysis. Risks of biases within the included RCTs may limit the credibility of the present results. Furthermore, the immunosuppressive regimens in the trials varied, including leflunomide plus steroids, cyclophosphamide plus steroids and steroids alone. Further research is required to compare MMF with other immunosuppressant regimens. Additionally, the present study investigated publication bias using funnel plots and Egger's regression analysis, which may have low power to distinguish bias when the included number of trials is small.

In conclusion, the present meta-analysis of the most recent evidence demonstrated that MMF was superior to placebo and may have similar efficacy compared with other immunosuppressants for inducing renal remission in patients with $\operatorname{Ig} \mathrm{AN}$. MMF may not add to the risks of adverse events. The effect of MMF on the long-term prognosis of patients with IgAN requires verification in further research.

\section{Acknowledgements}

The authors would like to thank all the researchers of the original trials included in the present meta-analysis.

\section{Funding}

This study was funded by the National Natural Science Foundation Young Investigator Grant Program (grant no. 81500525) and the Natural Science Foundation of Liaoning Province (grant no. 2014021046).

\section{Availability of data and materials}

The analyzed data generated during the study are available from the corresponding author on reasonable request.

\section{Authors' contributions}

LL designed, supervised and mentored the present study; JZ and TB acquired the data; and LL, JZ and LZ performed statistical analysis. The final version of the manuscript was read and approved by all the authors.

\section{Ethics approval and consent to participate}

Not applicable.

\section{Patient consent for publication}

Not applicable.

\section{Competing interests}

The authors declare that they have no competing interests.

\section{References}

1. Wyatt RJ and Julian BA: IgA Nephropathy. N Engl J Med 368: 2402-2414, 2013.

2. O'Shaughnessy MM, Hogan SL, Thompson BD, Coppo R, Fogo AB and Jennette JC: Glomerular disease frequencies by race, sex and region: Results from the international kidney biopsy survey. Nephrol Dial Transplant: Jul 2, 2017 (Epub ahead of print).

3. Moriyama T, Tanaka K, Iwasaki C, Oshima Y, Ochi A, Kataoka H, Itabashi M, Takei T, Uchida K and Nitta K: Prognosis in IgA nephropathy: 30 -year analysis of 1,012 patients at a single center in Japan. PLoS One 9: e91756, 2014.

4. Rasche FM, Keller F, Rasche WG, Schiekofer S, Boldt A, Sack U and Fahnert J: Why, when and how should immunosuppressive therapy considered in patients with immunoglobulin A nephropathy? Clin Exp Immunol 186: 115-133, 2016.

5. Jonsson CA and Carlsten H: Mycophenolic acid inhibits inosine 5'-monophophate dehydrogenase and suppresses immunoglobulin and cytokine production of B cells. Int Immunopharmacol 3: 31-37, 2003

6. Allison AC and Eugui EM: Mycophenolate mofetil and its mechanisms of action. Immunopharmacology 47: 85-118, 2000.

7. Lee SH, Kim CD, Huh KH, Cho BH, Ju MK, Lee DR, Cho HR, Park JW, Lee JJ, Lee S, et al: Low-dose mycophenolate mofetil in tablet form or capsule form combined with tacrolimus in the early period after kidney transplantation: A prospective randomized trial. Clin Nephrol 86: 319-327, 2016.

8. Glander P, Hambach P, Braun KP, Fritsche L, Waiser J, Mai I, Neumayer $\mathrm{HH}$ and Budde K: Effect of mycophenolate mofetil on IMP dehydrogenase after the first dose and after long-term treatment in renal transplant recipients. Int J Clin Pharmacol Ther 41: 470-476, 2003.

9. Hou JH, Le WB, Chen N, Wang WM, Liu ZS, Liu D, Chen JH, Tian J, Fu P, Hu ZX, et al: Mycophenolate mofetil combined with prednisone versus full-dose prednisone in $\operatorname{IgA}$ nephropathy with active proliferative lesions: A randomized controlled trial. Am J Kidney Dis 69: 788-795, 2017. 
10. Hogg RJ, Bay RC, Jennette JC, Sibley R, Kumar S, Fervenza FC, Appel G, Cattran D, Fischer D, Hurley RM, et al: Randomized controlled trial of mycophenolate mofetil in children, adolescents, and adults with IgA nephropathy. Am J Kidney Dis 66: 783-791, 2015.

11. Liu X, Dewei D, Sun S, Xu G, Liu H, He L and Zhang P: Treatment of severe $\operatorname{Ig}$ A nephropathy: Mycophenolate mofetil/prednisone compared to cyclophosphamide/prednisone. Int J Clin Pharmaco Ther 52: 95-102, 2014.

12. Liu XW, Li DM, Xu GS and Sun SR: Comparison of the therapeutic effects of leflunomide and mycophenolate mofetil in the treatment of immunoglobulin A nephropathy manifesting with nephrotic syndrome. Int J Clin Pharmacol Ther 48: 509-513, 2010.

13. Tang SC, Tang AW, Wong SS, Leung JC, Ho YW and Lai KN: Long-term study of mycophenolate mofetil treatment in IgA nephropathy. Kidney Int 77: 543-549, 2010.

14. Tang S, Leung JC, Chan LY, Lui YH, Tang CS, Kan CH, Ho YW and Lai KN: Mycophenolate mofetil alleviates persistent proteinuria in IgA nephropathy. Kidney Int 68: 802-812, 2005.

15. Frisch G, Lin J, Rosenstock J, Markowitz G, D'Agati V, Radhakrishnan J, Preddie D, Crew J, Valeri A and Appel G: Mycophenolate mofetil (MMF) vs placebo in patients with moderately advanced IgA nephropathy: A double-blind randomized controlled trial. Nephrol Dial Transplant 20: 2139-2145, 2005.

16. Maes BD, Oyen R, Claes K, Evenepoel P, Kuypers D, Vanwalleghem J, Van Damme B and Vanrenterghem YF: Mycophenolate mofetil in IgA nephropathy: Results of a 3-year prospective placebo-controlled randomized study. Kidney Int 65 : 1842-1849, 2004

17. Chen X, Chen P, Cai G, Wu J, Cui Y, Zhang Y, Liu S and Tang L: A randomized control trial of mycophenolate mofeil treatment in severe IgA nephropathy. Zhonghua Yi Xue Za Zhi 82: 796-801, 2002 (In Chinese).

18. Du B, Jia Y, Zhou W, Min X, Miao L and Cui W: Efficacy and safety of mycophenolate mofetil in patients with IgA nephropathy: An update meta-analysis. BMC Nephrol 18: 245, 2017.

19. Vecchio M, Bonerba B, Palmer SC, Craig JC, Ruospo M, Samuels JA, Molony DA, Schena FP and Strippoli GF: Immunosuppressive agents for treating $\operatorname{Ig} \mathrm{A}$ nephropathy. Cochrane Database Syst Rev 2015: CD003965, 2015.

20. Chen Y, Li Y, Yang S, Li Y and Liang M: Efficacy and safety of mycophenolate mofetil treatment in IgA nephropathy: A systematic review. BMC Nephrol 15: 193, 2014.

21. Xu G, Tu W, Jiang D and Xu C: Mycophenolate mofetil treatment for IgA nephropathy: A meta-analysis. Am J Nephrol 29: 362-367, 2009.
22. Higgins JP and Green S (eds): Cochrane handbook for systematic reviews of interventions, version 5.1.0. The Cochrane Collaboration, 2011. http://handbook.cochrane.org. Updated March 2011.

23. Knobloch K, Yoon U, Vogt PM: Preferred reporting items for systematic reviews and meta-analyses (PRISMA) statement and publication bias. J Craniomaxillofac Surg 39: 91-92, 2011.

24. Deierhoi MH, Kauffman RS, Hudson SL, Barber WH, Curtis JJ, Julian BA, Gaston RS, Laskow DA and Diethelm AG: Experience with mycophenolate mofetil (RS61443) in renal transplantation at a single center. Ann Surg 217: 476-484, 1993.

25. Rovin BH: Lupus nephritis: Guidelines for lupus nephritis-more recommendations than data? Nat Rev Nephrol 8: 620-621, 2012.

26. Conti F, Ceccarelli F, Perricone C, Massaro L, Cipriano E, Pacucci VA, Truglia S, Miranda F, Morello F, Alessandri C, et al: Mycophenolate mofetil in systemic lupus erythematosus: Results from a retrospective study in a large monocentric cohort and review of the literature. Immunol Res 60: 270-276, 2014

27. Langman LJ, LeGatt DF, Halloran PF, and Yatscoff RW Pharmacodynamic assessment of mycophenolic acid-induced immunosuppression in renaltransplant recipients. Transplantation 62: 666-672, 1996.

28. Park JS, Kim GH, Jo CH, Kim S, Lee CH, Kim YS and Kang CM: Effect of mycophenolic acid on cyclosporin A-induced fibronectin expression in rat mesangial cells. Pharmacology 91: 20-28, 2013.

29. Dubus I, Vendrely B, Christophe I, Labouyrie JP, Delmas Y, Bonnet $\mathbf{J}$ and Combe $\mathrm{C}$ : Mycophenolic acid antagonizes the activation of cultured human mesangial cells. Kidney Int 62: $857-867,2002$.

30. Hauser IA, Renders L, Radeke HH, Sterzel RB and Goppelt-Struebe M: Mycophenolate mofetil inhibits rat and human mesangial cell proliferation by guanosine depletion. Nephrol Dial Transplant 14: 58-63, 1999.

31. Al Hussain T, Hussein $\mathrm{MH}$, Al Mana $\mathrm{H}$ and Akhtar $\mathrm{M}$ : Pathophysiology of IgA Nephropathy. Adv Anat Pathol 24: 56-62, 2017.

32. Lai KN: Pathogenesis of IgA nephropathy. Nat Rev Nephrol 8: 275-283, 2012.

33. Beckwith H, Medjeral-Thomas N, Galliford J, Griffith M, Levy J, Lightstone L, Palmer A, Roufosse C, Pusey C, Cook HT and Cairns T: Nephrol Dial Transplant 32 (Suppl 1): i123-i128, 2017.

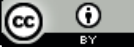

This work is licensed under a Creative Commons Attribution 4.0 International (CC BY 4.0) License. 